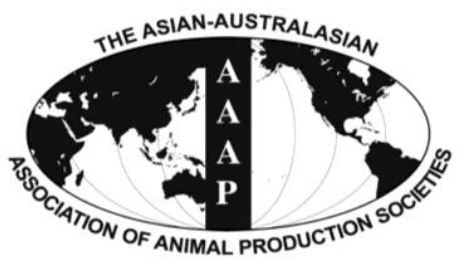

Asian Australas. J. Anim. Sci.

Vol. 26, No. 10 : 1459-1465 October 2013

http://dx.doi.org/10.5713/ajas.2013.13220

www.ajas.info

pISSN 1011-2367 elSSN 1976-5517

\title{
Effects of Methylcellulose on Fibrolytic Bacterial Detachment and In vitro Degradation of Rice Straw
}

\author{
Min Ji Kimª , Ha Guyn Sung ${ }^{1, a}$, Santi Devi Upadhaya, Jong K. Ha, and Sung Sill Lee ${ }^{2, *}$ \\ Department of Agriculture Biotechnology and Research Institute for Agriculture and Life Sciences, \\ College of Agriculture and Life Science, Seoul National University, Seoul 151-742, Korea
}

\begin{abstract}
Two in vitro experiments were conducted to evaluate the effect of methylcellulose (MC) on i) bacterial detachment from rice straw as well as ii) inhibition of bacterial attachment and fiber digestibility. To evaluate the effect of MC on fibrolytic bacterial detachment (Exp 1), in vitro bacterial cultures with $0.1 \%(\mathrm{w} / \mathrm{v}) \mathrm{MC}$ solution were compared with cultures without $\mathrm{MC}$ after $8 \mathrm{~h}$ incubation. The effect of MC on inhibition of bacterial attachment was determined by comparing with real-time PCR the populations of $F$. succinogenes, $R$. flavefaciens and $R$. albus established on rice straw pre-treated with $0.1 \%$ MC with those on untreated straw after incubation for 0,6 and $12 \mathrm{~h}$ (Exp 2). The major fibrolytic bacterial attachment on rice straw showed significantly lower populations with either the addition of MC to the culture or pre-treated rice straw compared to controls $(\mathrm{p}<0.05)$. Also, the digestibility of rice straw with MC was significantly lower compared with control $(\mathrm{p}<0.05)$. The F. succinogenes population did not show detachment from rice straw, but showed an inhibition of attachment and proliferation on rice straw in accordance with a decrease of fiber digestion. The detachments of Ruminococcus species co-existed preventing the proliferations with subsequent reduction of fiber degradation by MC during the incubation. Their detachments were induced from stable colonization as well as the initial adhesion on rice straw by $\mathrm{MC}$ in in vitro ruminal fermentation. Furthermore, the detachment of $R$. albus was more sensitive to MC than was R. flavefaciens. These results showed the certain evidence that attachment of major fibrolytic bacteria had an effect on fiber digestion in the rumen, and each of fibrolytic bacteria, F. succinogenes, R. flavefaciens and $R$. albus had a specific mechanism of attachment and detachment to fiber. (Key Words: Methylcellulose, Bacterial Detachment, Fiber Digestion, F. succinogenes, R. flavefaciens, $R$. albus)
\end{abstract}

\section{INTRODUCTION}

Based on their inhabiting environments, rumen bacteria are categorized as i) free-living bacteria in rumen liquid, ii) bacteria loosely attached to feed particles, iii) bacteria firmly adhered to feed particles, iv) bacteria associated with rumen epithelium, and v) bacteria attached to protozoa and fungal sporangia (Cheng and Costerton, 1980; Czerkawski and Cheng, 1988; McAllister et al., 1994). Microbes in rumen liquid (20 to $30 \%$ of total microbes) including freeliving bacteria and bacteria detached from solid substrate, have little direct involvement in insoluble feed particles

\footnotetext{
* Corresponding Author: Sung Sill Lee. Tel: +82-55-772-1883, Fax: +82-55-772-1889, E-mail: 1ss@gnu.ac.kr

1 Department of Animal Science and Technology, Sangji University, Wonju, 220-702, Korea.

2 Division of Applied Life Science and IALS, Gyeongsang National University, Jinju 660-701, Korea.

${ }^{a}$ These authors made an equal contribution to this paper. Submitted Apr. 16, 2013; Accepted Jun. 4, 2013; Revised Jun. 24, 2013
}

digestion (Miron et al., 2001). Microbes lived by attaching to feed particles (compartment 2 and 3) are numerically predominant (70 to $80 \%$ of microbial matter and microbial ATP production) and play a key role in feed particle digestion in the rumen (Craig et al., 1987; Miron et al., 2001; Trabalz Marinucci et al., 2006). Fibrolytic microbes such as $F$. succinogenes, $R$. flavefaciens, and $R$. albus are responsible for fibrin degradation as the primary degraders of forage cell walls (Windham and Akin, 1984; McAllister et al., 1994; Sung et al., 2007; Wang et al., 2012). Their attachments on plant tissues for fiber digestion were closely related with enzyme activity (Brock et al., 1982; Williams and Strachan, 1984; Michalet-Doreau et al., 2001; Hwang et al., 2008) and mutant cells lacking the adhesion ability were not effective in digesting fiber (Miron et al., 1998; Reddy and Morrison, 1998; Miron and Forsberg, 1999). Sodiumcarboxymethylcellulose (CMC) and methylcellulose (MC) did strongly inhibit both the adhesion of the major rumen fibrolytic species to fibrous feed particle (Kudo et al., 1987; Rasmussen et al., 1989; Roger et al., 1990), and cellulose 
degradation (McAllister et al., 1994; Miron et al., 2001). In the previous studies, MC was used for bacterial detachment in the rumen (Kudo et al., 1987; Ranila and Carro, 2003; Martinez et al., 2009), the objective of this study was to evaluate the effect of MC on fibrolytic bacterial detachment from particles and/or attachment and rice straw digestion in the rumen.

\section{MATERIALS AND METHODS}

\section{In vitro experiments and substrates}

Three cannulated Holstein steers $(740 \pm 10 \mathrm{~kg}$ body weight) were used as donors of rumen fluid for in vitro experiments. Timothy and concentrate in the ratio of 60 to 40 were fed at $2 \%$ of body weight twice a day (09:00 and 17:00). The rumen contents were collected from the fistulated steers after $1 \mathrm{~h}$ of morning feeding. Rumen fluid containing the ingesta was homogenized with a mixer (Mini mixer, Hanil, Korea) under $\mathrm{O}_{2}$-free $\mathrm{CO}_{2}$ gas, and then filtered through 8 layers of cheesecloth. Rice straw was ground through a $2 \mathrm{~mm}$ screen and dried after washing with hot distilled water to removing dust particles.

\section{Incubation}

Sixty $60 \mathrm{~mL}$ of rumen fluid-buffer mixture, comprising McDougall buffer and rumen liquor in the ratio of 2 to 1 , was dispensed anaerobically into $120 \mathrm{~mL}$ of serum bottles, filled with $\mathrm{O}_{2}$-free $\mathrm{CO}_{2}$ gas, containing $0.5 \mathrm{~g}$ of substrate, and then capped with a rubber stopper. The serum bottles were held in a shaking incubator at $39^{\circ} \mathrm{C}$.

\section{Experimental design}

Exp. 1: Experiment 1 was conducted to evaluate the effect of Methylcellulose (MC) addition on bacterial detachment and fiber digestibility during rumen fermentation. The rumen culture was incubated with rice straw as the substrate for $8 \mathrm{~h}$. MC $(0.1 \% \mathrm{w} / \mathrm{v})$ was added to one half of the rumen cultures after $8 \mathrm{~h}$ incubation and all cultures were incubated for a total of $48 \mathrm{~h}$. Methylcellulose solution was prepared by dissolving methylcellulose powder (Sigma Mo262) in boiling water.

Exp. 2: Experiment 2 was conducted to evaluate the effect of methylcellulose pre-treatment on bacterial attachment and fiber degradation. The rumen culture was prepared without pre-treated substrate for control and with MC pretreatment for the test cultures. Pre-treated substrates were prepared by soaking the ground rice straw in $0.1 \%$ of methylcellulose solution for $16 \mathrm{~h}$ and dried at $65^{\circ} \mathrm{C}$ for $72 \mathrm{~h}$. The triplicate cultures were sampled to analyze bacterial attachment and rice straw digestibility after 0,6 , and $12 \mathrm{~h}$ of incubation.

\section{Quantification of fibrolytic rumen bacteria with quantitative real-time PCR \\ Sample preparation: The culture was centrifuged at 160} $\times \mathrm{g}$ for $10 \mathrm{~min}$ to separate rice straw and culture medium. Collected rice straw was suspended in $50 \mathrm{~mL}$ of $0.9 \%$ saline solution and centrifuged three times at $160 \times \mathrm{g}$ for $10 \mathrm{~min}$ to remove easily detachable bacteria. After centrifugation, rice straw was dried using a lyophilizer (Ilshin, Korea) and kept at $-80^{\circ} \mathrm{C}$ until analysis of bacterial population.

DNA extraction: gDNA was extracted according to the method described by Purdy et al. (1996). $0.5 \mathrm{~g}$ of dried rice straw was mixed with $0.35 \mathrm{~mL}$ of TE buffer $(10 \mathrm{mM}$ Tris $\mathrm{HCl}, 1 \mathrm{mM}$ EDTA, pH 8.0), $0.5 \mathrm{~mL}$ of Tris-buffered phenol and $0.25 \mathrm{~g}$ of sterilized glass beads $(0.5 \mathrm{~mm}$, BioSpec. Product Inc. USA). The tubes were shaken for $2 \mathrm{~min}$, stood on ice for $2 \mathrm{~min}$ and this step was repeated three times. After adding $40 \mu \mathrm{L}$ of $10 \%$ sodium lauryl sulfate solution, tubes were centrifuged at $13,000 \times \mathrm{g}$ for $2 \mathrm{~min}$ and supernatant was collected. The remaining pellet was resuspended in $20 \mu \mathrm{L}$ of TE buffer, then centrifuged at $13,000 \times \mathrm{g}$ for $2 \mathrm{~min}$ and the supernatant was collected. gDNA was collected from pooled supernatant using a hydroxyapatite chromatography column (Hydroxyapatite Bio-Gel HTP Gel, Bio-Rad Laboratories, Inc, USA). The RNA was removed by DNAse-free pancreatic RNAse A treatment and subsequent gel filtration (MicroSpin S-200 HR Columns, Amersham Biosciences, UK). The Purity and concentration of gDNA were checked using a Biomate 5 spectrophotometer (Thermo Spectronic, USA).

PCR primer: Species-specific PCR primer sets for $F$. succinogenes, $R$. flavefaciens and $R$. albus were selected from a previous study (Koike and Kobayashi, 2001). Primers for $F$. succinogenes, $R$. flavefaciens, and $R$. albus were: Fs219f (5'-GGT ATG GGA TGA GCT TGC-3') and Fs654r (5'-GCC TGC CCC TGA ACT ATC -3'); Rf154f (5'- TCT GGA AAC GGA TGG TA-3') and Rf425r (5'CCT TTA AGA CAG GAG TTT ACA A-3'); Ra1281f (5'CCC TAA AAG CAG TCT TAG TTC G-3') and Ra1439r (5'-CCT CCT TGC GGT TAG AAC A-3'), respectively. Amplification sizes from the 3 bacterial species were 446, 259 and $175 \mathrm{bp}$ and annealing temperatures were 62, 55 and $55^{\circ} \mathrm{C}$, respectively.

Real-time PCR: gDNA was amplified and quantified with real-time PCR (RT-PCR)(Bio-Rad Inc. USA). The iQ Syber Green Supermix (Bio-Rad INC. USA) was used for RT-PCR amplification according to the manufacturer's protocol. RT-PCR conditions were: one cycle of initial denaturation at $95^{\circ} \mathrm{C}$ for $3 \mathrm{~min}, 40$ cycles of denaturation at $95^{\circ} \mathrm{C}$ or $30 \mathrm{~s}$, followed by annealing at each temperature of strains for $30 \mathrm{~s}$ and then an extension at $72^{\circ} \mathrm{C}$ for $30 \mathrm{~s}$. Thereafter, the melting point of RT-PCR product was 
analyzed to detect specificity of application. The melting curve was obtained by a $0.1^{\circ} \mathrm{C} / \mathrm{s}$ increase of heating temperature from 65 to $95^{\circ} \mathrm{C}$ with fluorescence detection at $0.1^{\circ} \mathrm{C}$ intervals.

The bacterial population was defined as the log copy number of $16 \mathrm{~S}$ rDNA which was calculated from a standard curve of control plasmid. The control plasmid had an insert of a specific fragment of $16 \mathrm{~S}$ rDNA amplified with primers specific to each species ( $F$. succinogenes, $R$. flavefaciens, and $R$. albus). The control plasmid was constructed by using pGEM-T Easy Vector System (Promega, USA) according to the manual procedure. The standard curves were respectively made by plotting $C_{t}$ values for serial dilutions of the control plasmid for each species.

\section{Analysis of DM digestibility and pH}

The DM digestibility was calculated by the difference between dry matter of undigested feed particles before and after incubation. The undigested feed particles were filtered through filter paper (Whatman No. 4) and washed for 3 times by distilled water, and then dried at $65^{\circ} \mathrm{C}$ for $72 \mathrm{~h}$. The $\mathrm{pH}$ was measured using a $\mathrm{pH}$ meter (Mettler Delta 340, Mettler Electronics, UK) before collection of undigested feed particles for detecting DM digestibility.

\section{Statistical analysis}

The data were analyzed according to a complete randomized design with a one-way analysis of variance of $\mathrm{pH}$ treatment. The statistical model was: $\mathrm{Y}_{\mathrm{ij}}=\mu_{\mathrm{i}}+\mathrm{T}_{\mathrm{ij}}$, where $\mathrm{i}$ was the number of treatments and $\mathrm{j}$ was the number of replication tubes. When the overall treatment effect was significant $(\mathrm{p}<0.05)$, the differences between treatment means were tested with the LSD test using the SAS program (SAS, 1996).

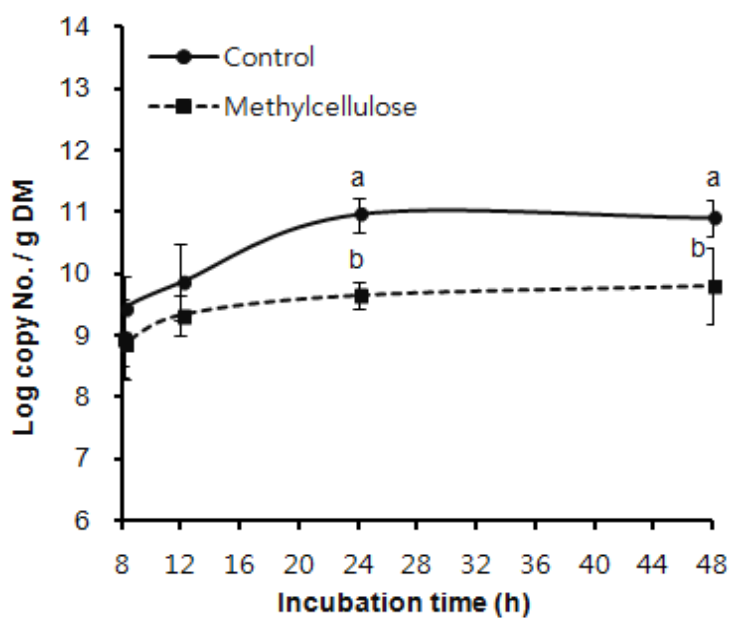

Figure 1. Detachment of Fibrobacter succinogenes on rice straw as influenced by MC addition after $8 \mathrm{~h}$ of incubation. ${ }^{\mathrm{a}, \mathrm{b}}$ Means with different letters differ significantly $(\mathrm{p}<0.05)$.

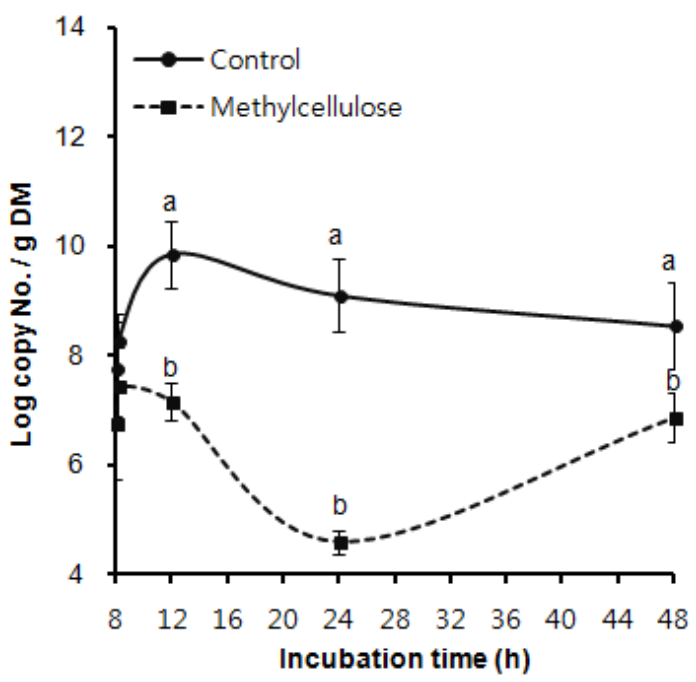

Figure 2. Detachment of Ruminococcus albus on rice straw as influenced by MC addition after $8 \mathrm{~h}$ of incubation. ${ }^{\mathrm{a}, \mathrm{b}}$ Means with different letters differ significantly $(\mathrm{p}<0.05)$.

\section{RESULTS}

Effect of methycellulose addition on bacterial detachment and fiber digestibility during the in vitro rumen fermentation

Bacterial detachments from fiber particles by methylcellulose addition: The populations of $F$. succinogenes, $R$. flavefaciens, and $R$. albus attaching to rice straw substrate after addition of $0.1 \%$ methylcellulose (MC) solution and $8 \mathrm{~h}$ incubation are shown in Figure 1, 2 and 3, respectively. Although no variation was obtained in $F$. succinogenes attachment between the control and treatment $10 \mathrm{~min}$ after the addition of methyl cellulose, a significant difference $(\mathrm{p}<0.05)$ was obtained between the control and treatment $4 \mathrm{~h}$ after MC addition (Figure 1).

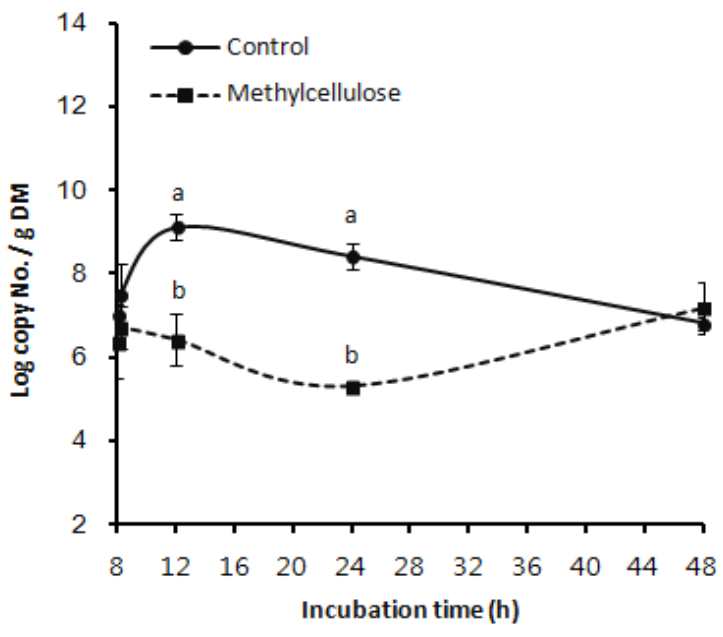

Figure 3. Detachment of Ruminococcus flavefaciens on rice straw as influenced by $\mathrm{MC}$ addition after $8 \mathrm{~h}$ of incubation. ${ }^{\mathrm{a}, \mathrm{b}}$ Means with different letters differ significantly $(\mathrm{p}<0.05)$. 
The populations of $R$. albus (Figure 2) and $R$. flavefaciens (Figure 3) attachment was also not different between control and treatment $10 \mathrm{~min}$ after MC addition. However, the attachment of both strains abruptly dropped after $4 \mathrm{~h}$ following $\mathrm{MC}$ addition ( $12 \mathrm{~h}$ incubation), reached the minimum level at $24 \mathrm{~h}$ incubation and then gradually increased until $48 \mathrm{~h}$ incubation. The attachment of $R$. flavefaciens and $R$. albus clearly showed that bacteria detachment from rice straw was due to MC addition. Also, $R$. albus seemed to show a more sensitive response to detachment compared to $R$. flavefaciens.

Effect of methylcellulose addition on degradation of rice straw in rumen: The degradation of rice straw and $\mathrm{pH}$ in the in vitro rumen fermentation was affected by the addition of $\mathrm{MC}$ as shown in Figure 4 and 5, respectively. The degradation of rice straw gradually increased with the time of incubation and showed similar trends between control and treatment until $12 \mathrm{~h}$ incubation after the $\mathrm{MC}$ addition (Figure 4). Fiber degradation following MC addition occurred slowly compared to control after $12 \mathrm{~h}$ incubation and was significantly lower than the control $(p<0.05)$. This result clearly indicated that $\mathrm{MC}$ inhibited the degradation of fiber in rumen. The $\mathrm{pH}$ of in vitro culture media gradually decreased during $48 \mathrm{~h}$ incubation and showed a similar trend in control and treatment. Although the $\mathrm{pH}$ was numerically lower in treatment compared with control after $12 \mathrm{~h}$ incubation, no significant difference was observed.

\section{Effect of methylcellulose pre-treatment on bacterial attachment and fiber degradation}

Bacterial attachments on pre-treated rice straw by methylcellulose: The attachment of the major species of fibrolytic bacteria on the pre-treated rice straw are presented in Figure 6, 7 and 8. The attachment of $F$. succinogenes,

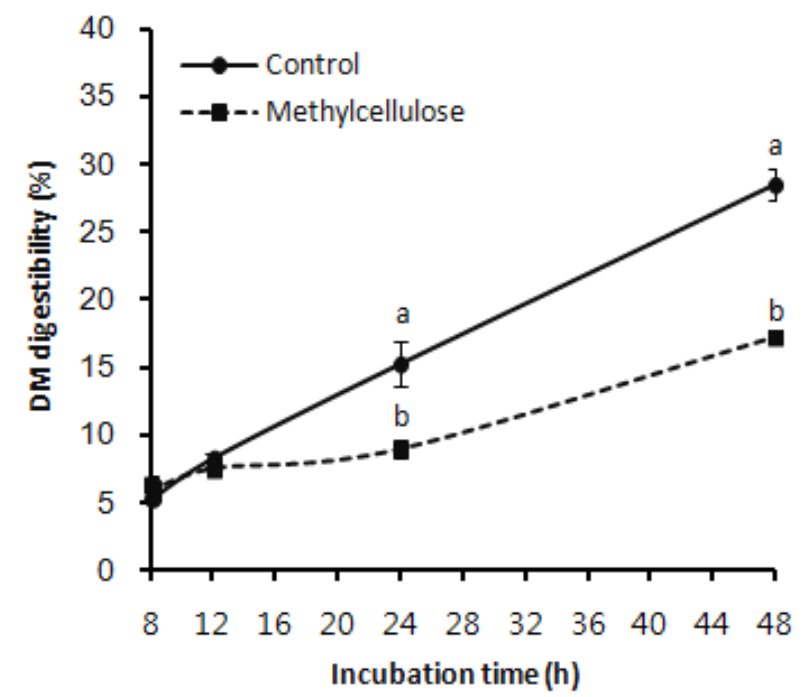

Figure 4. The DM digestibility of rice straw as influenced by methylcellulose addition after $8 \mathrm{~h}$ of incubation. ${ }^{\mathrm{a}, \mathrm{b}}$ Means with different letters differ significantly $(\mathrm{p}<0.05)$.

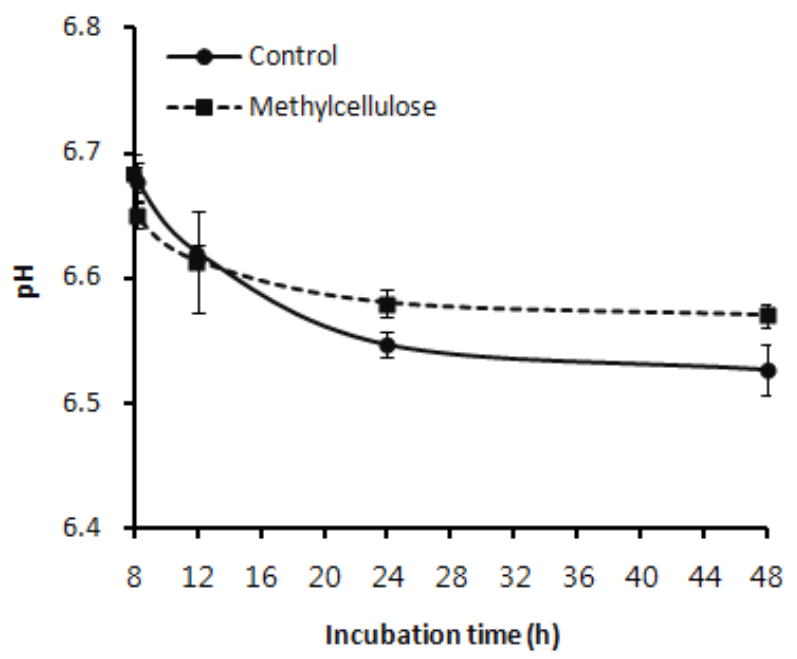

Figure 5. Change in $\mathrm{pH}$ as influenced by methylcellulose addition after $8 \mathrm{~h}$ of incubation.

$R$. albus, and $R$. flavefaciens on the non-treated rice straw gradually increased during the incubation, while the attachment of these species on pre-treated rice straw was clearly inhibited. In the case of $R$. albus (Figure 7) and $R$. flavefaciens (Figure 8), the attached bacterial populations were not different between the control and the pre-treatment at the initial incubation time $\left(\begin{array}{ll}0 & \mathrm{~h}\end{array}\right)$. However, their populations in the pre-treatment groups abruptly decreased after $6 \mathrm{~h}$ incubation, and showed a significant difference between control and pre-treatment at 6 and $12 \mathrm{~h}$ incubation $(p<0.05)$. The bacterial populations response to pretreatment indicated that MC prevented the stable colonization after initial attachment, Similar patterns were also observed in the detachments following the initial attachment in $R$. albus and $R$. flavefaciens.

Degradation of pre-treated rice straw by methylcellulose addition: The degradation of MC pretreated rice straw is presented in Figure 9. The degradation of rice straw gradually increased in the course of incubation

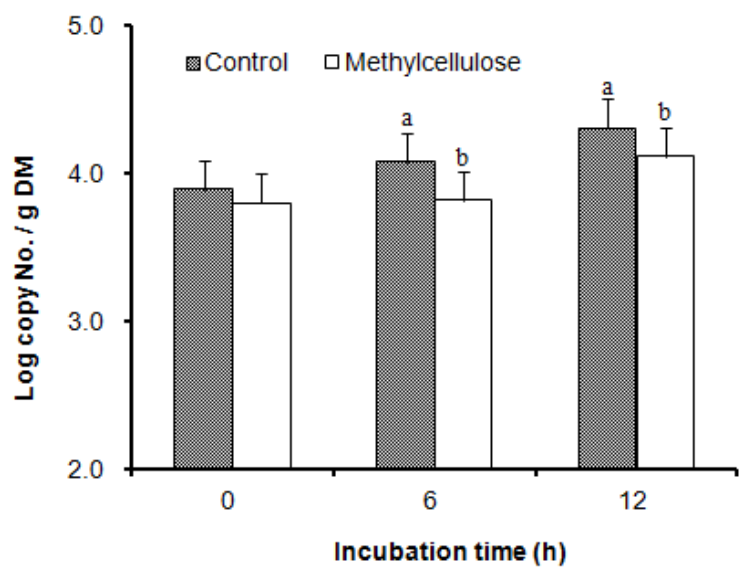

Figure 6. Attachment of Fibrobacter succinogenes as influenced by rice straw pre-treatment with MC (methylcellulose). ${ }^{\mathrm{a}, \mathrm{b}}$ Means with different letters differ significantly $(\mathrm{p}<0.05)$. 


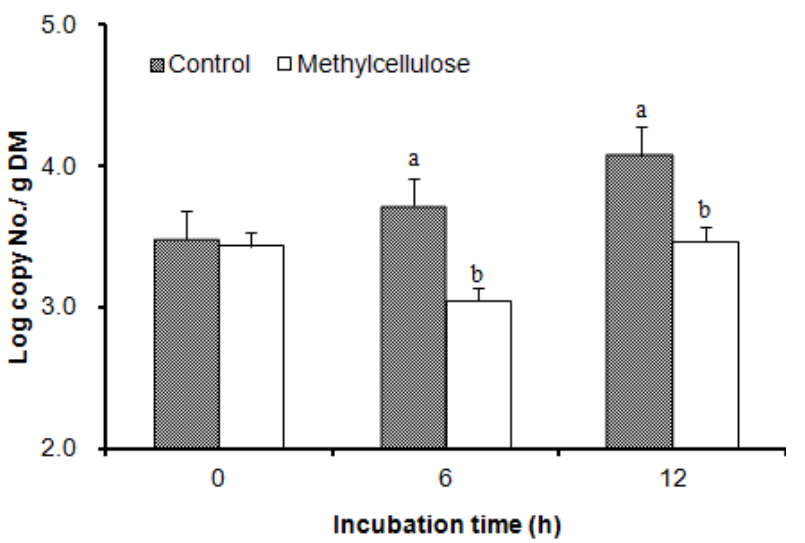

Figure 7. Attachment of Ruminococcus albus as influenced by rice straw pre-treatment with MC (methylcellulose). ${ }^{\mathrm{a}, \mathrm{b}}$ Means with different letters differ significantly $(\mathrm{p}<0.05)$.

time in both control and pre-treatment. This result indicated that fiber degradation was prevented by pre-treatment of MC the same as it was by MC addition in middle of incubation in the rumen bacterial fermentation.

\section{DISCUSSION}

Kudo et al. (1987) reported the electron microscopic observations that MC mediated the occurrence of detachments from and the prevention of attachment to cellulose fiber by fibrolytic bacteria in the rumen. Many researchers have been interested in the phenomenon of the fibrolytic processes of microbes in the presence of various effectors including negative factors such as low temperature (Minato and Suto, 1978; Gong and Forsberg, 1989; Minato et al., 1993), low pH (Sung et al., 2007), presence of $\mathrm{O}_{2}$ (Miron et al., 2001), deprivation of $\mathrm{Ca}^{+2}$ and $\mathrm{Mg}^{+2}$, (Roger et al., 1990) and presence of sodium-carboxymethylcellulose (CMC) or methylcellulose (MC) (Rasmussen et al., 1989; Bhat et al., 1990) and Tween 80 (Akin, 1980).

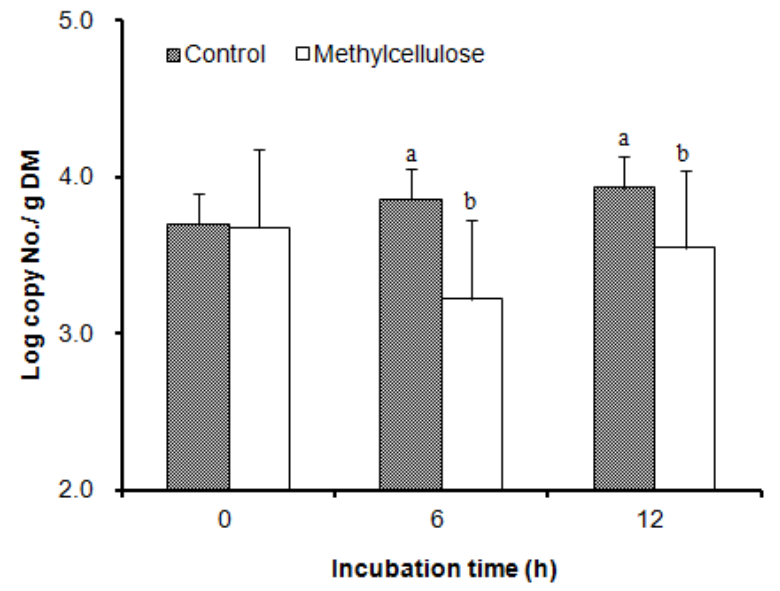

Figure 8. Attachment of Ruminococcus flavefaciens as influenced by rice straw pre-treatment with MC (methylcellulose). ${ }^{\mathrm{a}, \mathrm{b}}$ Means with different letters differ significantly $(\mathrm{p}<0.05)$.
In this study, the addition of $\mathrm{MC}$ in the middle of incubation (Figures 1, 2 and 3) and the MC pre-treated fibrous particles (Figures 6, 7 and 8) in in vitro ruminal fermentation, clearly showed that major fibrolytic bacteria became detached from the substrate as well as the inhibition of bacteria attachment on fibrous particles during the digestive process. Their detachments and attachment inhibition by the addition of MC were reported in previous studies (Minato and Suto, 1978; Kudo et al., 1987; Bhat at al., 1990; Miron et al., 2001). Also, Cheng et al. (1991) reported that the attachment of fibrolytic rumen fungi was blocked by the addition of MC which did not affect the growth of these organisms with soluble substrates. Since Kudo et al. (1987) mentioned that MC was an effective agent for detaching the major species of rumen fibrolytic bacteria from their cellulosic substrate, other researchers have used MC to evaluate procedures and techniques to detach particle-associated microbes from ruminal digesta (Ranilla and Carro, 2003; Trabalza-Marinucci et al., 2006; Martínez et al., 2009). Bhat et al. (1990) reported that the degree of inhibition by MC was similar for $F$. succinogenes and $R$. flavefaciens, Our result relating to $F$. succinogenes attachment showed a different response trend to inhibition of attachment without the detachment phenomenon (Figures 1 and 4), while $R$. albus (Figures 2 and 7) and $R$. flavefaciens (Figures 3 and 8) underwent detachment with the addition of MC. Furthermore, R. albus showed a more sensitive response to detachment after the stable colonization (Figures 2 and 3) as well as in the initial adhesion (Figures 6, 7, and 8) compared with $R$. flavefaciens with the addition of MC. This study showed the importance of attachment in fiber digestion by the addition of MC, which inhibited degradation of rice straw with the co-occurrence of inhibition of fibrolytic bacterial attachment to the fibrous substrate (Figures 4 and 9). Minato and Suto (1978) reported that MC prevents the

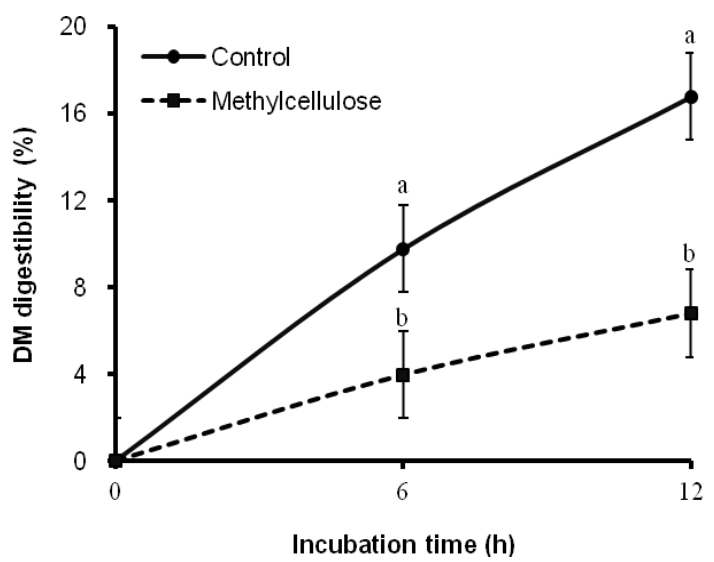

Figure 9. DM digestibility of rice straw as influenced by pretreatment with MC (methylcellulose). ${ }^{\mathrm{a}, \mathrm{b}}$ Means with different letters differ significantly $(\mathrm{p}<0.05)$. 
attachment of fibrolytic ruminal bacteria to cellulose and inhibits cellulose digestion. Other researchers (Kudo et al., 1987; Pell and Schofield, 1993) demonstrated that MC mediated detachment of fibrolytic rumen bacteria from cellulose without affecting enzyme activity but nevertheless blocked cellulose degradation. Also, Rasmussen et al. (1988) showed that MC strongly inhibited cellulose degradation by several species of fibrolytic bacteria of ruminal origin and specifically, the growth of $R$. flavefaciens was completely inhibited at $0.1 \%(\mathrm{w} / \mathrm{v})$ of $\mathrm{MC}$. The necessity of adhesion for subsequent fiber digestion by fibrolytic ruminal bacteria was additionally supported by observations that mutant cells, which had lost most of their fibrolytic capability, were smoother in appearance of surface topology compared to wild type cells (Stewart et al., 1990; Miron et al., 1998; Reddy and Morrison, 1998). Furthermore, a low ruminal $\mathrm{pH}$ (5.7) was responsible for higher numbers of fibrolytic bacterial detachment from fibrous substrate than the optimum ruminal pH 6.7 (Sung et al., 2007).

In conclusion, the result obtained in this study showed that both addition of $\mathrm{MC}$ and the pre-treatment of fibrous particles by MC solution induced detachment after stable colonization as well as the initial adhesion of $F$. succinogenes, $R$. flavefaciens, and R. albus.

\section{ACKNOWLEDGEMENTS}

This research was supported by Bio-industry Technology Development Program, Ministry of Agriculture, Food \& Rural Affairs, and Cooperative Research Program for Agriculture Science \& Technology Development, Rural Development Administration, Republic of Korea.

\section{REFERENCES}

Akin, D. E. 1980. Evaluation by electron microscopy and anaerobic culture of types of rumen bacteria associated with digestion of forage cell walls. Appl. Environ. Microbial. 39:242-252.

Bhat, S., R. J. Wallace, and E. R. Ørskov. 1990. Adhesion of cellulolytic ruminal bacteria to barley straw. Appl. Environ. Microbiol. 56:2698-2703.

Brock, F. M., C. W. Forsberg, and J. G. Buchanan-Smith. 1982. Proteolytic activity of rumen microorganisms and effects of proteinase inhibitors. Appl. Environ. Microbiol. 44:561-569.

Cheng, K. -J. and J. W. Costerton. 1980. Adhesive bacteria-Their role in the digestion of plant material, urea and epithelial cells. In: Digestive Physiology and Metabolism in Ruminants (Ed. Y. Ruckebusch and P. Thivend). MTP press Ltd., Lancaster, England. pp. 225-250.

Cheng, K. -J., H. Kudo, S. H. Duncan, A. Mesbah, C. S. Stewart, A. Bernalier, G. Fonty, and J. W. Costerton. 1991. Prevention of fungal colonization and digestion of cellulose by the addition of methylcellulose. Can. J. Microbiol. 37:484-487.

Craig, W. M., G. A. Broderick, and D. B. Ricker. 1987. Quantitation of microorganisms associated with the particulate phase of ruminal ingesta. J. Nutr. 117:56-62.

Czerkawski, J. W. and K. -J. Cheng. 1988. Compartmentation in the rumen. In: The Rumen Microbial Ecosystem (Ed. P. N. Hobsn). Elsevier Science Publishing, New York, USA, pp. 361. Gong, J. and C. W. Forsberg. 1989. Factors affecting adhesion of Fibrobacter succinogenes S85 and adherence defective mutants to cellulose. Appl. Environ. Microbiol. 55:3039-3044.

Hwang, I. H., C. H. Lee, S. W. Kim, H. G. Sung, S. Y. Lee, S. S. Lee, H. Hong, Y. -C. Kwan, and J. K. Ha. 2008. Effects of mixtures of Tween80 and cellulolytic enzymes on nutrient digestion and cellulolytic bacterial adhesion. Asian-Aust. J. Anim. Sci. 21:1604-1609.

Koike, S. and Y. Kobayshi. 2001. Development and use of competitive PCR assays for the rumen cellulolytic bacteria: Fibrobacter succinogenes, Ruminococcus albus and Ruminococcus flavefaciens. FEMS Microbiol. Lett. 204:361366.

Kudo, H., K. -J. Cheng, and J. W. Costerton. 1987. Electron microscopic study of the methylcellulose-mediated detachment of cellulolytic rumen bacteria from cellulose fibers. Can. J. Microbiol. 33:267-272.

Martínez, M. E., M. J. Ranilla, S. Ramos, M. L. Tejido, C. Saro, and D. C. Carro. 2009. Evaluation of procedures for detaching particle-associated microbes from forage and concentrate incubated in Rusitec ferrmenters: Efficiency of recovery and representativeness of microbial isolates. J. Anim. Sci. 87:20642072.

McAllister, T. A., H. D. Bae, G. A. Jones, and K. -J. Cheng. 1994. Microbial attachment and feed digestion in the rumen. J. Anim. Sci. 72:3004-3018.

McDougall, E. I. 1948. Studies on ruminant saliva. 1. The composition and output of sheep's saliva. Biochem. J. 43:99109.

Michalet-Doreau, B., I. Fernandez, C. Peyron, L. Millet, and G. Fonty. 2001. Fibrolytic activities and cellulolytic bacterial community structure in the solid and liquid phases of rumen contents. Reprod. Nutr. Dev. 41:187-194.

Minato, H. and T. Suto. 1978. Technique for fractionation of bacteria in rumen microbial ecosystem. II. Attachment of bacteria isolated from bovine rumen to cellulose powder in vitro and elution of bacteria attached therefrom. J. Gen. Appl. Microbiol. 24:1-16.

Minato, H., M. Mitsumori, and K. -J. Cheng. 1993. Attachment of microorganisms to solid substrates in the rumen. Pages 139145 in Proc. MIE Bioforum on Genetics, Biochemistry and Ecology of Lignocellulose Degradation. Institut Pasteur, Paris, France.

Miron, J. and C. I. Forsberg. 1999. Characterization of cellulose binding proteins which are involved in adhesion mechanism of Fibrobacter intestinalis DR7. Appl. Microbiol. Biotechnol. 51:491-497.

Miron, J., D. Ben-Ghedalia, and M. Morrison. 2001. Invited Review: Adhesion mechanisms of rumen cellulolytic bacteria. J. Dairy Sci. 84:1294-1309.

Miron, J., E. Morag, E. A. Bayer, R. Lamed, and D. Ben-Ghedakia. 
1998. An adhesion defective mutant of Ruminococcus albus SY3 is impaired in its capability to degrade cellulose. J. Appl. Microbiol. 84:249-254.

Pell, A. N. and P. Schofield. 1993. Microbial adhesion and degradation of plant cell walls. Pages 397-423 in Forage Cell Wall Structure and Digestibility (Ed. R. D. Hatfield, H. G. Jung, J. Ralph, D. R. Buxton, D. R. Mertens, and P. J. Weimer). ASA-CSSA-SSSA, Madison, WI.

Purdy, K. J., T. M. Embley, S. Takii, and D. B. Nedwell. 1996. Rapid extraction of DNA and rRNA from sediments by a novel hydroxyapatite spin-colum method. Appl. Environ. Microbiol. 62:3905-3970.

Ranilla, M. J. and M. D. Carro. 2003. Diet and procedure used to detach particle-associated microbes from ruminal digesta influence chemical composition of microbes and estimation of microbial growth in Rusitec fermenters. J. Anim. Sci. 81:537544

Rasmussen, M. A., B. A. White, and R. B. Hespell. 1989. Improved assay for quantitating adherence of ruminal bacteria to cellulose. Appl. Environ. Microbiol. 55:2089-2091

Rasmussen, M. A., R. B. Hespell, B. A. White, and R. J. Bothast. 1988. Inhibitory effects of methylcellulose on cellulose degradation by Ruminococcus flavefaciens. Appl. Environ. Microbiol. 54:890-897.

Reddy, S. K. K. and M. Morrison. 1998. Biochemical and molecular characterization of adherence-defective mutants of Ruminococcus albus strain 8. Page 132 in Proc. MIE Bioforum on Cellulose Degradation, Institut Pasteur, Paris, France.
Roger, V. R., G. Fonty, S. Komisarczuk-Bony, and P. Gouet. 1990. Effects of physicochemical factors on the adhesion to cellulose avicel of the rumen bacteria Ruminococcus flavefaciens and Fibrobactor succinogenes subsp. succinogenes. Appl. Environ. Microbiol. 56:3081-3087.

Statistical Analysis System Institute. 1996. SAS/STATTM User's Guide: Statistics, Version 7, 5th Edition. Vol. 3, Cary, NC.

Stewart, C. S., S. H. Duncan, and H. J. Flint. 1990. The properties of forms of Ruminococcus flavefaciens which differ in their ability to degrade cotton cellulose. FEMS Microbiol. Lett. 72:47-50.

Sung, H. G., Y. Kobayashi, J. Chang, A. Ha, I. H. Hwang, and J. K. Ha. 2007. Low ruminal $\mathrm{pH}$ reduces dietary fiber digestion via reduced microbial attachment. Asian-Aust. J. Anim. Sci. 20:200-207.

Trabalza-Marinucci, M., C. Poncet, E. Delval, and G. Fonty. 2006. Evaluation of techniques to detach particle-associated microorganisms from rumen contents. Anim. Feed Sci. Technol. 125:1-16.

Wang, Y., J. E. Ramirez-Bribiesca, L. J. Yanke, A. Tsang, and T. A. McAllister. 2012. Effect of exogenous fibrolytic enzyme application on the microbial attachment and digestion of barley straw in vitro. Asian-Aust. J. Anim. Sci. 25:66-74.

Williams, A. G. and N. H. Strachan. 1984. Polysaccharide degrading enzymes in microbial populations from the liquid and solid fractions of bovine rumen digesta. Can. J. Anim. Sci. 64:58-59.

Windham, W. R. and D. E. Akin. 1984. Rumen fungi and forage fiber degradation. Appl. Environ. Microbiol. 48:473-476. 